\title{
ROMELE, A. Digital Hermeneutics. London and New YORK: ROUTLEDGE, 2020
}

Angelo Milhano ${ }^{1}$

ROMELE, A. Digital Hermeneutics. London and New York: Routledge, 2020

No decorrer das duas primeiras décadas do século XXI, a hermenêutica confrontou-se com um novo desafio. Um desafio que foi lançado pela disseminação e utilização massivas dos meios e tecnologias digitais, por sua vez capazes de determinar o modo como cada sujeito constrói, compreende, e interage com o seu mundo. A ubiquidade do digital delimitou um novo enquadramento da questão da interpretação, sobre o qual a Hermenêutica tem obrigatoriamente que reflectir, seja no sentido de problematizar a influência do digital sobre a interpretação e compreensão humanas, seja enquanto via metodológica que permite compreender e clarificar os processos interpretativos que são já inerentes aos meios e tecnologias com os quais o ser humano se encontra hoje, em constante interacção.

O texto Hermenêutica Digital (Digital Hermeneutics, 2020), propóese fazer isso mesmo. Com ele, Alberto Romele começa por sublinhar que uma abordagem hermenêutica, estritamente ontológica, aos problemas da interpretação que se levantam no contexto do digital não se constitui, por si só, como uma base sólida para uma reflexão aprofundada sobre o tema (ROMELE, 2020, p. 6). Tendo em mente as diferenças substanciais que existem entre os vários dispositivos e plataformas sob as quais o digital se fundamenta empiricamente, Romele considera que uma hermenêutica

1 Pesquisador no Phenomenology and Culture Group - Praxis: Centre of Philosophy, Politics and Culture/University of Évora, Évora - Portugal. https://orcid.org/0000-0001-9830-6224 Email: a.s.n.milhano@gmail.com

https://doi.org/10.1590/0101-3173.2021.v44dossier.15.p265

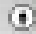

This is an open-access article distributed under the terms of the Creative Commons Attribution License. 
do digital, se se pretende verdadeiramente universal, necessita de se afastar da sua abordagem tradicional, estritamente ontológica, e atentar sobre as particularidades materiais que determinam o funcionamento do digital (ROMELE, 2020, p. 7-8).

Em muito inspirado pela "via longa" da hermenêutica de Paul Ricoeur, Romele procura construir uma hermenêutica do digital que, ao longo da primeira parte do texto, se debruça sobre a dimensáo empírica dos dispositivos e plataformas digitais, articulando-a, de seguida, com uma delimitação ontológica dos problemas hermenêuticos que daí se levantam, e com a qual se irá ocupar na segunda parte do texto. Ao atentar sobre essa inextricável bidimensionalidade do digital, i.e., sobre o seu desdobramento, simultaneamente, empírico e ontológico, Romele acaba por determiná-lo, não apenas como uma instância de mediação da relação que se estabelece entre o homem e o mundo, mas como um domínio independente capaz de construir uma interpretação que lhe é própria, e pela qual compreende, reconfigura, e também transforma, o sujeito e o mundo com os quais se relaciona (ROMELE, 2020, p. 9-12).

Ao longo do primeiro capítulo de Hermenêutica Digital, esse domínio surge conceptualizado por Romele como uma representação, como uma construção do mundo que, embora nele se encontre empiricamente enraizado, pressupóe para com ele uma distância interpretativa, a partir da qual se torna possível traçar uma fronteira - embora bastante ténue - entre o digital e o real (ROMELE, 2020, p. 17-21). Alberto Romele toma assim uma posiçáo contra os autores que compreendem o humano na eminência de ser totalmente digitalizado, i.e., contra aqueles que descartam a possibilidade de uma distinção entre o digital e o real. Uma posição que se encontra claramente manifesta na crítica ao reducionismo que Romele considera inerente à Teoria Semântica da Informação de Luciano Floridi, pela qual se desenvolve uma concepção do real integralmente delimitada pelo seu carácter informativo (ROMELE, 2020, p. 27-35).

Contra tal posição, Romele vem defender que a construção do significado no contexto do digital não assenta apenas sobre o carácter informativo dos dados, uma vez que também este acaba por ser determinado por circunstâncias de carácter hermenêutico, as quais se encontram por sua vez manifestas na heterodeterminação dos seus conteúdos significativos. Na proposta de Romele, o significado que pode ser extraído da informação se encontra por isso dependente de um conjunto alargado de contextos e 
elementos que criam acerca dele múltiplas perspectivas, por seu turno também relativas ao sujeito que as interpreta, e que não podem ser, por isso, descartadas (ROMELE, 2020, p. 35-39), conforme se pode compreender das suas próprias palavras (ROMELE, 2020, p. 30):

Não existe uma informação que não possua um valor de verdade dentro de um contexto específico de utilização. Mesmo muitos dos dados perceptivos acabam por se demonstrar dependentes de um contexto extraperceptivo, linguístico, simbólico, cultural e pragmático (no final de contas, hermenêutico). Tal náo quer dizer que seja necessário optar por uma posição relativista, sobretudo uma vez que, por um lado, as coisas possuem as suas possibilidades, e que, por outro, a cultura, a linguagem, entre outros elementos, definem um enquadramento dentro do qual a informação assume um valor de verdade. ${ }^{2}$

No entanto, para Romele, considerar que existe uma fronteira entre o digital e o real não quer dizer que ambos os domínios não se encontrem interligados. Com o título "O Real Invadiu o Virtual", o segundo capítulo dá desde logo a entender essa interligação. $\mathrm{Na}$ introdução deste, Romele começa por fazer referência aos vários aspectos do digital que, no decorrer das últimas décadas, acabaram por ser transformados sob a influência que o contexto social, histórico e cultural sobre eles acabou por exercer (ROMELE, 2020, p. 43-46). No sentido inverso, Romele faz também referência aos vários modos pelos quais a vida quotidiana se encontra cada vez mais imersa no digital, e de como, a partir dessa relação, se tem vindo a criar uma nova forma de perspectivar as próprias relações sociais. $\mathrm{O}$ "rasto digital" que é criado aquando da utilização dos mais diversos dispositivos tecnológicos com os quais interagimos - e.g., o nosso histórico de pesquisas e navegação, o rasto criado com o uso de smartphones, wearables etc. - tem vindo a ser pressuposto por diversas áreas do conhecimento, especialmente no que diz respeito às ciências sociais, como um correlato digital da realidade social onde o ser humano se encontra lançado (ROMELE, 2020, p. 47-50).

Detendo-se sobre o trabalho que Bruno Latour desenvolve nesse sentido, Romele acaba por levantar uma importante questão epistemológica relativa à pressuposiçáo de uma homologia entre o registo digital dos dados e a realidade social, nomeadamente no que concerne ao problema da indiferenciaçáo entre o objecto de estudo e as metodologias de análise que estão em jogo no domínio da Sociologia Digital (ROMELE, 2020, p. 49). Muito embora

${ }^{2}$ A tradução de todas as citaçôes ao longo do texto é da nossa inteira responsabilidade. 
considere a Teoria Actor-Rede de Latour como uma proposta sociológica que perspectiva as relaçóes sociais, tanto na sua dimensão ontológica como material (ROMELE, 2020, p. 51) — pois atenta sobre a rede de relaçôes que se estabelecem entre os diversos actores sociais - Romele compreende que o mesmo não poderá ser dito acerca da concepçáo latouriana do digital. $\mathrm{Na}$ leitura de Romele (2020, p. 53):

A metafísica de Latour desdobra-se num duplo sentido; como uma metafísica da matéria $e$ como uma metafísica das redes. Enquanto, normalmente, essa ambivalência da metafísica se encontra num equilíbrio elegante (um equilíbrio com o qual, em grande medida, acabo por concordar), parece-me no entanto que, quando Latour se refere ao digital, tem tendência a favorecer as redes em detrimento da matéria. Como se as (re)presentaçóes digitais da realidade social fossem transparentes e "inocentes", como se elas não fossem apenas capazes de representar as coisas, mas também de apresentá-las como elas são.

Seguindo a proposta de Romele, a concepção latouriana do digital enquanto representação, "sem filtro", da realidade social, acaba mesmo por contradizer muitas das ideias sociológicas mais fundamentais da sua Teoria Actor-Rede (ROMELE, 2020, p. 54). Em Latour, os dispositivos e plataformas tecnológicas surgem conceptualizados a partir da rede de relaçóes que estabelecem, não apenas com os actores no contexto social no qual se desenvolvem, mas também com os próprios elementos empíricos que os definem como tais, i.e., na sua dependência social da matéria, da cultura, e da história. Contudo, e tendo em mente a sua concepção do digital, esse domínio acaba por apresentar-se aqui como desmaterializado e descontextualizado; concebido como uma "cópia fiel" da rede de relaçôes que se criam entre os vários actores sociais, uma rede sob a qual a Sociologia Digital deverá fundamentar a sua investigação (ROMELE, 2020, p. 55-59). Seguindo o argumento de Romele, na concepção do digital pressuposta em Bruno Latour, não existe, por isso, uma distinção clara entre o digital e o real, sendo que, por essa mesma via, o objecto e a metodologia da investigaçáo em Sociologia Digital acabam também por se confundir, colocando em causa toda a sua pretensa cientificidade.

A crítica que Romele lança à concepção do digital proposta por Latour desenvolve-se, por isso, no mesmo sentido da crítica dirigida a Floridi, no decorrer do primeiro capítulo. Tomando algumas das questôes técnicas que se levantam com o Big Data para fundamentar a sua posição, Romele termina o 
segundo capítulo defendendo que o significado inerente ao "rasto digital" que compóe os dados, ao contrário do que é pressuposto pela concepção do digital de Bruno Latour, é também ele hermenêutico (ROMELE, 2020, p. 59-63). Inspirando-se no trabalho de Simondon, Romele considera que, mais que uma tradução do real, o digital constitui-se, antes, como uma "transdução", como uma individuação do sentido, o qual, muito embora se pretenda como um reflexo exacto das relaçôes sociais que se estabelecem entre os vários actores, acaba, no entanto, por ser construído por via hermenêutica (ROMELE, 2020, p. 64-72). Numa clara referência à influência que a hermenêutica de Ricoeur exerce sobre a sua própria posição, Romele defende que o significado do "rasto digital", mais do que um espelho do mundo e das interacçôes que nele se dão entre os diversos actores sociais, resulta, antes, de um "enredo" (mise en intrigue), de um enquadramento interpretativo que torna os dados compreensíveis para um intérprete. Um processo que se demonstra, por isso, estruturalmente bastante próximo da noção ricoeuriana de mimesis (ROMELE, 2020, p. 75-78).

Com a primeira parte do seu texto, Romele delimita entáo o caráter epistemológico e metodológico da Hermenêutica, no contexto do digital. A dimensão empírica que aí se propóe irá agora articular-se com dimensão ontológica que ocupa o segundo momento do livro. Aqui, o autor propôe-se principalmente expandir a abordagem hermenêutica do digital, construindo para tal sobre uma "viragem ontológica" que coloca as propriedades interpretativas inerentes aos dispositivos tecnológicos e às plataformas digitais no centro do questionamento, delimitando-as a partir do conceito de emaginação (emagination) (ROMELE, 2020, p. 83). Ao compreender uma capacidade interpretativa nos meios e tecnologias digitais, a proposta avançada em Hermenêutica Digital acaba também por se afastar do carácter antropocêntrico que caracteriza as propostas mais tradicionais da Hermenêutica.

Romele coloca-se, assim, por essa via, no caminho de uma reformulação verdadeiramente universal dos seus pressupostos (ROMELE, 2020, p. 84-87). No intuito de delimitar os processos interpretativos que considera inerentes a alguns meios e tecnologias digitais, Romele dedica a atenção do terceiro capítulo ao conceito de "imaginação produtiva", a qual compreende como base esquemática dos processos que operam a síntese interpretativa. Remontando as raízes da concepção moderna da "imaginação produtiva" à determinação transcendental kantiana que dela é feita, Romele compreende que "o digital, 
tal como hoje se encontra formulado, não diz apenas respeito aos processos de registo de dados, e por isso à memória, mas também à própria imaginação" (ROMELE, 2020, p. 89). Na defesa dessa ideia, Romele procura, em primeiro lugar, dar a compreender ao leitor de Hermenêutica Digital como a "imaginação produtiva" humana é, também ela, algo que se dá "fora das nossas cabeças" (ROMELE, 2020, p. 121), materializada em símbolos, metáforas e narrativas (ROMELE, 2020, p. 93), sem contudo deixar de sublinhar o papel crítico que ela desempenha, aquando da síntese interpretativa.

A síntese interpretativa operada por via da "imaginação produtiva" à qual Romele se refere, poderá ser compreendida, ainda mais claramente, através de uma pequena incursão pelas etapas que compóem a tríplice mimesis de Paul Ricoeur (p. 93-94). De acordo com esta, a interpretação apresenta-se como um processo que começa por criar 1) uma "prefiguração" do sentido, pela qual se reconhecem quais os elementos significativos que já se encontram no mundo, e também a forma como estes se podem articular entre si. Daí, esses elementos são 2) "configurados", sintetizando-se temporalmente a sua heterogeneidade sob um "enredo" (mise en intrigue). O significado acaba então por se construir aquando 3) da "refiguraçáo" do objecto que resulta do "enredo", i.e., na relação que o objecto significativo resultante estabelece com a subjectividade que é inerente aos contextos social, histórico e também cultural, com os quais acaba por interagir (ROMELE, 2020, p. 93-96).

Todo esse processo, por se revelar dependente de elementos externos, i.e., do "mundo" que fornece os elementos significativos que irão compor a interpretação, demonstra para Romele como a faculdade da "imaginação produtiva" não pode ser compreendida apenas como algo interno à mente humana; que o esquematismo inerente à "imaginação produtiva" não pode compreender-se como um processo que reside naquelas que Romele, citando Kant, designa como as "profundezas da alma humana" (ROMELE, 2020, p. 87, 96, 109). A “imaginação produtiva”, pela qual se opera a síntese interpretativa, depende, por isso, tanto do sujeito intérprete, que articula os elementos significativos da realidade numa síntese temporal, i.e., num "enredo", como do próprio mundo onde se encontram esses mesmos elementos e no qual se determinam também as suas possibilidades de relação significativa.

Romele compreende ainda que essa formulação da "imaginação produtiva” à luz da tríplice mimesis também se encontra manifesta no contexto da produção digital de sentido, sobretudo uma vez que os meios e tecnologias digitais se mostram já capazes de replicar fielmente os seus 
processos (ROMELE, 2020, p. 97). Propondo o conceito de emaginação (emagination) para definir os processos de síntese aí em jogo - especialmente no que concerne ao funcionamento dos algoritmos de processamento de dados - Romele compreende que o digital se apresenta, hoje, como um elemento criador de sentido, sobretudo na medida em que se mostra capaz de operar uma "síntese do heterogéneo" que é representado pelo "rasto digital" criado aquando do emprego dos meios e tecnologias digitais - que, depois de "configurado" sob a forma de dados, se torna interpretável (ROMELE, 2020, p. 100-103). Para Romele, "as tecnologias digitais não são apenas interfaces entre a nossa imaginação e o mundo. Elas são, mais que isso, uma das formas (talvez hoje a principal) pela qual a 'imaginação produtiva' se externaliza e se realiza como tal, no mundo" (2020, p. 103).

No que diz respeito à sua delimitação digital enquanto "emaginação", o carácter hermenêutico da "imaginação produtiva" mostra-se, para Romele, na luz da dependência que todo o processo de transformação do "rasto digital" em dados possui para com o contexto social, histórico, e cultural que o determina. A liberdade criativa, a qual, na sua formulação mais tradicional, poderia ser usada como base para distinguir a "imaginação produtiva" humana da sua formulação enquanto "emaginação", acaba também por ser reformulada por essa via, pois, por se encontrar dependente de um conjunto de regras que determinam as suas possibilidades, a "imaginação produtiva", embora autónoma, acaba por ser compreendida sob um enquadramento que se encontra já delimitado pelo que existe. Fazendo recurso da terminologia de Levi Strauss, Romele (2020, p. 115) compreende por isso que, no que tange à imaginação, "nunca fomos engenheiros", apenas artesãos.

Nesse sentido, e não podendo ser compreendida como uma creatio ex nihilo, a "imaginaçáo" que Romele considera inerente, tanto aos seres humanos como a alguns dos meios e tecnologias digitais que se encontram hoje disponíveis, é assim definida como a capacidade de transformação e reconfiguração dos elementos significativos já existentes no "mundo", sempre de acordo com o contexto hermenêutico que determina as suas possibilidades de correlação:

A liberdade consiste menos numa questão de libertação, e muito mais na possibilidade de recombinar, e por aí renegociar, as fronteiras do ambiente sócio-técnico que nos envolve. Por outras palavras, os seres humanos são essencialmente hetero-determinados, e aquilo que designamos de "liberdade" pressupóe um longo e árduo desvio pela nossa exterioridade 
tecnológica, mas também pela nossa exterioridade corporal, cultural, e social (ROMELE, 2020, p. 109).

Todos os objectos interpretativos são, por isso, o resultado de uma recombinação de elementos que já existem no mundo; uma recombinação que, no digital, é construída por via da emaginação (ROMELE, 2020, p. 115125). Ora, quando compreendida sob o prisma do "esquematismo" kantiano, a emaginação - e.g., no caso dos algoritmos de processamento Big Data, de Inteligência Artificial, entre outros possíveis - revela-se mesmo capaz de ultrapassar, em vários aspectos, a "imaginação produtiva" do ser humano (ROMELE, 2020, p. 130-132).

Como conclusão do quarto capítulo, Romele debruça-se ainda sobre as várias fases de desenvolvimento da hermenêutica digital, que considera em muitos aspectos similares aos níveis interpretativos que compóem a abordagem hermenêutica da natureza. Romele faz, sobretudo, por destacar como 1) a hermenêutica digital começou por criar uma circunscrição do digital como um objecto passivo, alvo da investigação hermenêutica; passando para a sua 2) determinação como medium interpretativo, através do qual se torna possível ao sujeito criar uma interpretação do "mundo"; culminado com 3) a problematizaçáo hermenêutica das capacidades interpretativas autónomas que são inerentes aos próprios meios e tecnologias digitais (ROMELE, 2020, p. 137-140).

No decorrer de Hermenêutica Digital, Romele apresenta então uma concepção da Hermenêutica que se edifica sobre uma posição fundamentalmente crítica. Muito embora a sua proposta compreenda uma distinção entre o digital e o real, ela não deixa, contudo, de se debruçar sobre as questôes que se levantam em torno da correlação que se estabelece entre esses dois domínios. Para terminar o texto, Romele propóe, por isso, uma importante reflexão acerca do problema da indiferença que a humanidade manifesta, perante a crescente influência que a emaginação possui sobre as representaçóes sociais do sujeito. Essa indiferença, conforme ele concebe, manifesta-se em dois sentidos: 1) aquela que as tecnologias interpretativas - e.g., algoritmos de processamento de Big Data e Inteligência Artificial — possuem para com a subjectividade de cada ser humano que representam digitalmente, e 2) a que o ser humano, seu utilizador, possui perante a crescente influência que essas representaçóes digitais exercem sobre si e sobre a sua compreensão do mundo (ROMELE, 2020, p. 145-146). Nas palavras de Romele (2020, p. 152): 
[...] há dois elementos que caracterizam o habitus digital: (1) primeiro, que as práticas dos algoritmos e do Big Data são indiferentes ao sujeito, visto que operam em um nível infraindividual, na medida em que desmembram os indivíduos em algumas das suas tendências, gostos etc. Mas também porque operam a um nível supraindividual, uma vez que organizam esses elementos em categorias gerais; (2) segundo, embora seja indiferente para connosco, o digital continua a ser sobre nós muito influente. Propóe-nos continuamente imagens e imaginários das nossas identidades com os quais, em um certo nível, nos adaptamos inconscientemente, e que acabamos finalmente por tornar nossos.

O problema da indiferença surge assim perspectivado por Romele à luz de Pierre Bourdieu, nomeadamente na reformulação que propóe para o conceito bourdieusiano de habitus como "habitus digital". Enquanto o habitus (social) de Bourdieu se compreende, em linhas gerais, como "aquilo que nos faz querer o que a sociedade nos permite ter" (ROMELE, 2020, p. 150), i.e., como a delimitação conceptual do processo pelo qual se opera uma identidade social, paralelamente, o "habitus digital" de Romele refere-se ao modo como, aquando da utilização dos meios e tecnologias digitais, estes se mostram capazes de construir uma representaçáo do sujeito, i.e., um "perfil", criado a partir dos hábitos do utilizador que ficam registados sobre as plataformas digitais, i.e., uma identidade digital.

O problema que Romele compreende aqui manifesto materializase na forma como os processos de representação digital, os quais operam hermeneuticamente sobre o "habitus digital", acabam por se mostrar permeáveis aos interesses económicos e políticos que sobre eles se impóem. $\mathrm{Na}$ medida em que podem ser influenciados por esse tipo de interesses, os algoritmos que regem o funcionamento dos meios e tecnologias digitais acabam por processar o "habitus digital" de um utilizador, de acordo com os pressupostos determinados por esses interesses. O sujeito, por via desse processo, acaba por ser digitalmente representado sob o espectro do consumo, perfilado conforme os traços gerais que compóem o seu "habitus digital", ficando a sua identidade desprovida da subjectividade que o distingue como o sujeito que ele é. O problema revela-se, pois, no modo como a indiferença que o algoritmo manifesta para com sujeito acaba também por se repercutir sobre ele e sobre as suas concepçóes do "mundo" (ROMELE, 2020, p. 149-152). 
Para Romele, os meios e tecnologias digitais que hoje temos ao nosso dispor são, por isso, e em grande medida, "máquinas geradoras de habitus" (ROMELE, 2020, p. 151). Com o problema da indiferença que aí se fundamenta, é a própria liberdade humana que acaba por ser colocada em causa. Na conclusão de Hermenêutica Digital, Romele acaba por defender uma educação para o digital, uma consciencialização social para os seus perigos, que, quando devidamente institucionalizada, se mostra capaz de promover a liberdade pessoal, assim como uma atitude crítica e consciente, capaz de confrontar os processos construção e representação padronizados do sujeito que imperam nesse contexto.

Segundo Romele, uma educação para o digital apresenta-se ainda como a melhor resposta que pode ser dada no combate à indiferença que, por essa via, se tem vindo a disseminar, sempre de maneira a evitar as suas mais nefastas repercussóes sobre o sujeito e sobre a comunidade onde este se encontra lançado (ROMELE, 2020, p. 155-158). Num contexto histórico e social onde o digital acabou por se transformar numa parte incontornável, não só das relaçóes sociais que estabelecemos, mas também da construção de nossa própria individualidade, Hermenêutica Digital apresenta-se como uma obra de incontornável importância. Não apenas pelos contributos que fornece para o contexto da investigaçáo que se desenvolve actualmente, em Filosofia da Tecnologia e nas restantes Humanidades que se ocupam com o digital, mas também para as áreas de investigação e desenvolvimento tecnológico que se ocupam com o design e construção dos meios e tecnologias sob os quais o digital se fundamenta empiricamente. Para estas, Hermenêutica Digital constitui uma obra que consegue, simultaneamente, enquadrar materialmente as questóes epistemológicas e metodológicas que se levantam com o desenvolvimento dos processos de interpretação digital, e também alertar para algumas importantes questôes éticas e humanas que daí vão acabar por se levantar.

\section{REFERÊNCIA}

ROMELE, A. Digital Hermeneutics. London and New York: Routledge, 2020

Recebido: 08/01/2021

Aceito: 16/02/2021 